\title{
Activation of BDNF signaling prevents the return of fear in female mice
}

\author{
Danay Baker-Andresen, Charlotte R. Flavell, Xiang Li, and Timothy W. Bredy ${ }^{1}$ \\ Psychiatric Epigenomics Laboratory, Queensland Brain Institute, The University of Queensland, Brisbane, Queensland 4072, Australia
}

\begin{abstract}
There are significant sex differences in vulnerability to develop fear-related anxiety disorders. Females exhibit twice the rate of post-traumatic stress disorder (PTSD) as males and sex differences have been observed in fear extinction learning in both humans and rodents, with a failure to inhibit fear emerging as a precipitating factor in the development of PTSD. Here we report that female mice are resistant to fear extinction, and exhibit increased DNA methylation of Bdnf exon IV and a concomitant decrease in mRNA expression within the medial prefrontal cortex. Activation of BDNF signaling by the trkB agonist 7,8-dihydroxyflavone blocks the return of fear in female mice after extinction training, and thus represents a novel approach to treating fear-related anxiety disorders that are characterized by a resistance to extinction and increased propensity for renewal.
\end{abstract}

There are significant sex differences in terms of vulnerability to develop fear-related anxiety disorders. Females exhibit twice the rate of post-traumatic stress disorder (PTSD) as males (Olff et al. 2007), which cannot be explained by the severity of the experienced trauma or comorbidity with other affective disorders (Tolin and Foa 2006). Furthermore, sex differences have been observed in fear extinction learning in humans and rodents, with a failure to inhibit fear emerging as a precipitating factor in the development of PTSD (Lebron-Milad et al. 2012; Ter Horst et al. 2012). In accordance with previous observations we have found that there are significant sex differences in the extinction of conditioned fear in mice. Male and naturally cycling female C57BL/6 mice ( $n=15-16 /$ group, 9 wk of age) were first trained on a cued-fear-conditioning task in which a 70-dB white noise (conditioned stimulus [CS], 2 min) coterminated with mild foot shock (unconditioned stimulus [US] $0.7 \mathrm{~mA}, 1 \mathrm{sec}$ ) on three occasions. Twenty-hours later, mice were extinction trained in a new context (30 nonreinforced, 2-min, 5-sec inter-trial interval, tone (CS) exposures in context B). On Day 3, all mice were returned to context $\mathrm{B}$ and tested (two CS presentations) for retention of memory for fear extinction. There was no difference between male and female mice in the acquisition of cued fear (data not shown). However, there was a significant sex difference in memory for the extinction of conditioned fear $\left(F_{(3,59)}=11.41, P<0.0001\right.$; Tukey's post hoc test: fear conditioned without extinction training (FC-No EXT) male vs. extinction trained (EXT) male, $P<0.0001$; EXT male vs. EXT female, $P<0.05$ ), with male mice exhibiting significantly lower levels of freezing than females (Fig. 1). These data suggest that female mice are resistant to the extinction of conditioned fear; however, the neural mechanisms underpinning this effect are not known.

Epigenetic mechanisms influence cognition and memory by regulating learning-induced gene expression (Day and Sweatt 2011). One such epigenetic mechanism is DNA methylation, which has been implicated in experience-dependent plasticity and in the formation and maintenance of fear-related memories (Miller et al. 2010; Baker-Andresen et al. 2012). Activity-dependent brain-derived neurotrophic factor (BDNF) signaling enhances neural plasticity and is necessary for the formation of

\section{'Corresponding author}

E-mail: t.bredy@uq.edu.au

Article is online at http://www.learnmem.org/cgi/doi/10.1101/Im.029520.112. fear-related memories (Peters et al. 2010; Andero and Ressler 2012) with the epigenetic regulation of $B d n f$ expression being shown to be critical for the acquisition and extinction of conditioned fear (Bredy et al. 2007). Furthermore, dysregulation of BDNF has been implicated in many neuropsychiatric disorders (Boulle et al. 2012). Recently, significant sex differences in BDNF signaling have been observed within the prefrontal cortex (Hill and van den Buuse 2011), a region of the brain in which sexual dimorphism in epigenomic function has also been reported $(\mathrm{Xu}$ et al. 2008). However, it is not yet known whether there are sex differences in the epigenetic regulation of $B d n f$, which would subsequently contribute to the observed differences in fear-related learning and memory. To address this issue, we measured the level of DNA methylation surrounding the transcription start site (TSS) of exon IV of the gene encoding BDNF by methylated DNA immunoprecipitation (MeDIP) followed by quantitative PCR (qPCR) (Fig. 2A). Briefly, genomic DNA was isolated from tissue samples encompassing the prefrontal cortex by overnight proteinase $\mathrm{K}$ treatment, phenol-chloroform extraction, ethanol precipitation, and RNase digestion. Prior to MeDIP, genomic DNA was randomly fragmented by sonication into fragments of $\sim 500$ bp in length, with $1 \mu \mathrm{g}$ fragmented DNA used for each MeDIP assay. MeDIP was performed using a MeDIP assay kit (Active Motif) as per the manufacturer's instructions. Methylated DNA fragments were recovered by reverse cross-link followed by ethanol precipitation and then quantified by qPCR using MEDIP-qPCR primers for $B d n f$ exon IV (forward, 5'-GTGGACTCCCACCCACTTT-3'; reverse, 5'-TATTACCTCCGCCATGCAAT-3').

In response to the extinction of conditioned fear, $B d n f$ expression is altered in an isoform-specific manner; $B d n f$ exon IV expression increases in response to fear extinction and is marked by learning-induced epigenetic modifications surrounding its promoter (Bredy et al. 2007). Furthermore, reduced BDNF exon IV expression is associated with deficits in inhibitory neurotransmission in the prefrontal cortex (Sakata et al. 2009), thus adversely affecting the formation and maintenance of extinction memories when occurring in the medial prefrontal cortex (ILPFC) (Akirav et al. 2006), an area of the brain that is critically involved in fear extinction. As opposed to examining the well-characterized promoter region of $B d n f$ exon IV, we selected a locus immediately downstream of TSS due to the presence of several binding motifs for transcription factors, including Sp1, YY1, and CTCF, all of which are known to interact with DNA methylation in regulating 


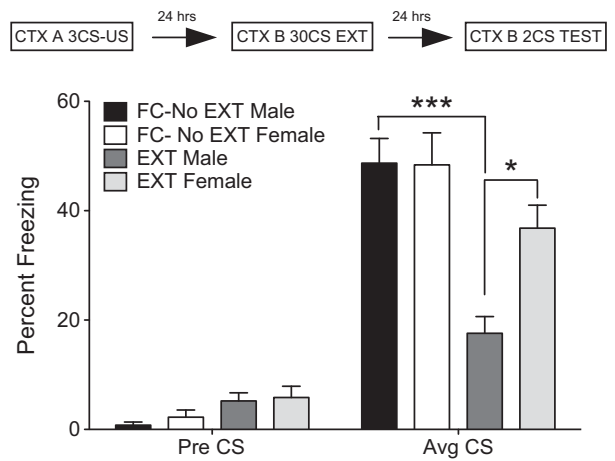

Figure 1. Female mice exhibit impaired retention of fear extinction memory compared to males. Twenty-four hours after a $30 \mathrm{CS}$ extinction session in context B, male mice (EXT male) freeze significantly less than no-extinction controls (FC-No EXT male) when presented with two CS in the extinction context, suggesting retention of the memory for extinction training. While no difference in the retention of fear is observed between sexes (FC-No EXT male vs. FC-No EXT female), female mice (EXT female) display a significant extinction impairment compared to extinguished males. $\left({ }^{* *}\right) P<0.0001,(*) P<0.05$.

transcriptional activity. As an indirect measure of the functional relevance of variations in DNA methylation, we also measured $B d n f$ exon IV mRNA expression within the ILPFC of naive male and female mice. Briefly, RNA was isolated from samples encompassing the ILPFC of naive male and female mice using the Trizol extraction method (Invitrogen). Total RNA (1 $\mu \mathrm{g})$ was used for cDNA synthesis using the Omniscript RT kit (Qiagen). PCR was then performed using primers for $B d n f$ exon IV (forward, 5'-GCAGCTGCCTTGATGTTTAC-3'; reverse, 5'-CCGTGGA CGTTTACTTCTTTC-3') and for phosphoglycerate kinase (Pgk) as an internal control (forward, 5'-TGC ACGCTTCAAAAGCGCACG-3'; reverse, 5'-AAGTCCACCCTCATCACGACCC-3'). qPCR was performed using a RotorGeneQ (Qiagen) cycler using SYBR-green (Qiagen). The threshold cycle for each sample was chosen from the linear range and converted to a starting quantity by interpolation from a standard curve run on the same plate for each set of primers. Bdnf exon IV mRNA levels were normalized for each well to Pgk mRNA using the $\Delta \Delta C T$ method, and each qPCR was run in duplicate for each sample and repeated at least two times. mRNA levels were analyzed by unpaired $t$-tests.

Our results revealed a significant sex difference in DNA methylation and mRNA expression. Naive female mice exhibited significantly greater methylation (unpaired $t$-test, $t=2.75, \mathrm{df}=7$, $P<0.05$ ) (Fig. 2C) relative to naive males, which was accompanied by decreased levels of $B d n f$ exon IV mRNA expression (unpaired $t$-test, $t=2.04, \mathrm{df}=6$, $P<0.05$ ) (Fig. 2B). Together, these data suggest a potential relationship between sex differences in the epigenetic regulation of $B d n f$ exon IV within the medial prefrontal cortex and fear extinction in mice. Therefore, we next asked whether these differences could collectively be overcome to promote the extinction of conditioned fear in female mice.

A brief reminder CS after fear conditioning renders the memory for that fear temporarily labile and sensitive to modification, requiring re-stabilization or updating of the memory trace through a process known as reconsolidation (Przybyslawski and Sara 1997; Przybyslawski et al. 1999; Nader et al. 2000). Monfils et al. (2009) capitalized on the labile nature of memory to introduce a retrieval-extinction procedure to interfere with reconsolidation and strengthen the formation of fear extinction memory in rats. They observed a significant reduction in the fear response that did not return as a function of spontaneous recovery, renewal, or reinstatement. These findings were subsequently replicated in humans (Schiller et al. 2010), and in mice in which a single nonreinforced CS prior to extinction training diminished the renewal of conditioned fear (Clem and Huganir 2010). However, not all studies have demonstrated beneficial effects using this approach, and an exaggerated return of fear, dependent on the context in which the fear memory is retrieved, has also been reported (Chan et al. 2010). Based on these observations, we reasoned that a retrieval-extinction protocol might be useful in promoting fear extinction in females, which are otherwise resistant when examined in a standard fear extinction training protocol. Moreover, as there are sex differences in the epigenetic regulation of cortical BDNF expression and in basal levels of BDNF expression in other structures of the fear extinction-related circuitry (Zhu et al. 2006), we hypothesized that fear extinction would be facilitated through direct systemic activation of the downstream signaling target of BDNF, the trkB receptor. 7,8-Dihydroxyflavone $(7,8$ DHF) is a small molecule activator that binds to the trkB receptor (Jang et al. 2010), thereby mimicking the effect of BDNF in the brain. Systemic administration of 7,8-DHF has been shown to activate trkB receptors, enhance learning and memory (Liu et al. 2010; Andero et al. 2011, 2012), and reverse memory deficits in
A

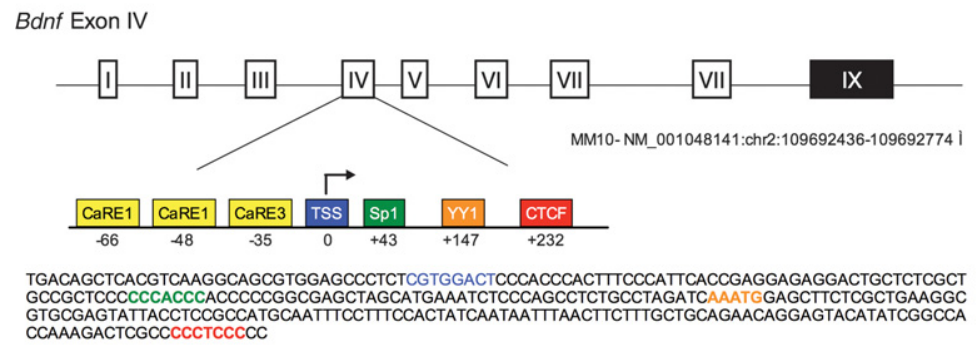

B
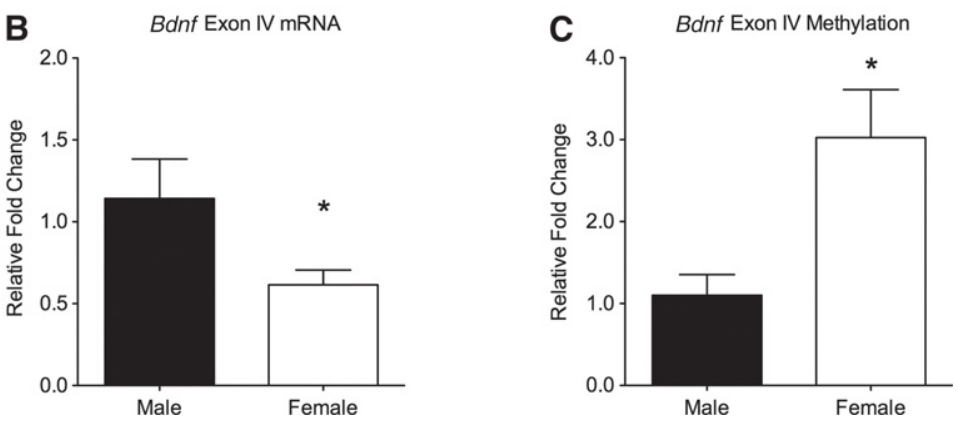

Figure 2. Expression of $B d n f$ exon IV mRNA differs in naive males and female $C 57 \mathrm{BL} / 6$ mice and is accompanied by differences in DNA methylation surrounding TSS. (A) DNA methylation levels were measured at the TSS of exon IV of the gene encoding BDNF. A significant increase in methylation was observed in females $(C)$, along with a concurrent decrease in Bdnf exon IV expression (B), compared to males. $\left.{ }^{*}\right) P<0.05$ 
A
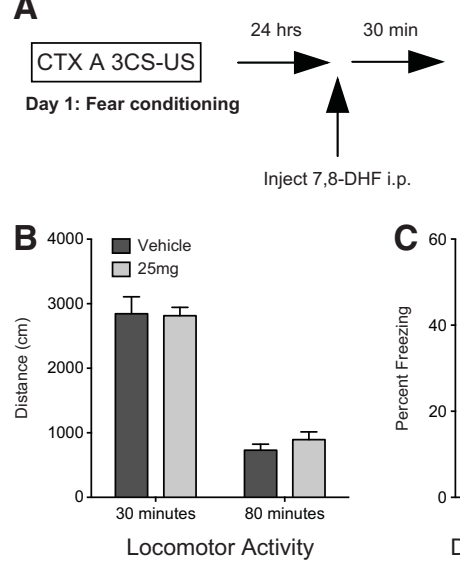

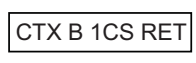

Day 2: Retrieval

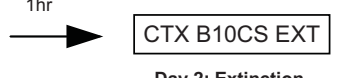

Day 2: Extinction

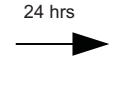

CTX B 2CS TEST

Day 3: Extinction Test

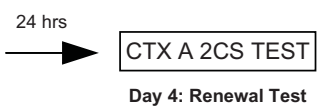

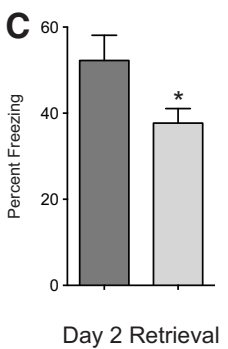

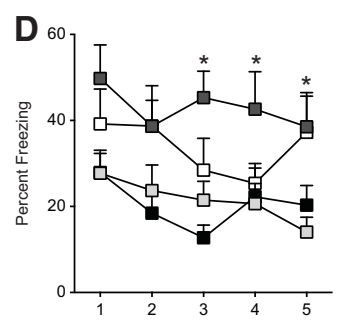

Day 2 Extinction (2CS bins)

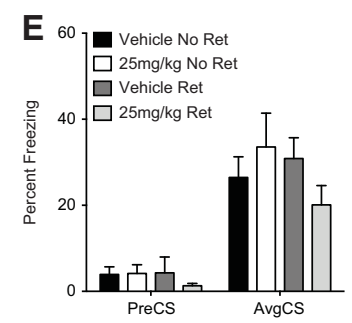

Day 3 Context B Test

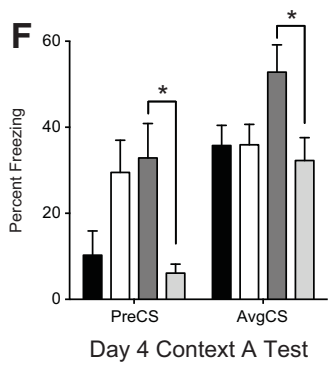

Figure 3. 7,8-Dihydroxyflavone prevents retrieval-induced renewal of fear. $(A)$ Schematic representation of experimental protocol. (B) Analysis of distance traveled 30 and 80 min post-injection with either vehicle (10\% DMSO in PBS) or $25 \mathrm{mg} / \mathrm{kg} 7,8$-DHF reveals no effect of drug on locomotor activity. (C) Treatment with 7,8-DHF 30 min prior to retrieval significantly decreased the expression of fear in female mice. (D) Vehicle-treated animals subjected to a retrieval cue (Vehicle Ret) demonstrate a resistance to extinction compared to drug-treated (25 mg/kg 7,8-DHF Ret) and nonretrieval groups (Vehicle No Ret and $25 \mathrm{mg} / \mathrm{kg} \mathrm{7,8-DHF} \mathrm{No} \mathrm{Ret).} \mathrm{(E)} \mathrm{No} \mathrm{significant} \mathrm{differences} \mathrm{were} \mathrm{observed} \mathrm{at} \mathrm{test} \mathrm{in} \mathrm{context} \mathrm{B.} \mathrm{(} F$ ) A significant retrieval-induced renewal of fear was observed in the vehicle retrieval group compared to nonretrieval groups, an effect which was blocked in the 7,8 -DHF Ret group. $(*) P<0.05$.

a preclinical model of age-related cognitive decline (Devi and Ohno 2012; Zeng et al. 2012a, b). We therefore investigated whether administration of 7,8-DHF, in combination with a modified version of the retrieval-extinction protocol, could aid in further promoting extinction in female mice.

Female mice ( $n=8$ /group) were trained on a cued-fear-conditioning task and $24 \mathrm{~h}$ later were exposed to a single retrieval cue prior to extinction training in a new context (10 or 11 nonreinforced tone exposures in context $\mathrm{B}$, balanced for CS exposure on retrieval). All mice were then returned to context $\mathrm{B}$ and tested for retention of memory for fear extinction on Day 3 before being tested for renewal of fear memory $24 \mathrm{~h}$ later in context A (Fig. 3A). We found that a single exposure to a retrieval cue, prior to fear extinction training, led to significantly higher levels of withinsession freezing, and an exaggerated return of fear when the mice were tested in the context in which fear was initially learned (Fig. 3F), similar to the findings of Chan et al. (2010). In contrast, there were no differences when tested in the extinction context $\mathrm{B}$ (Fig. 3E). A single injection of 7,8-DHF (25 mg/kg, i.p., dissolved in $10 \%$ DMSO in sterile saline), administered systemically 30 min prior to retrieval, led to a significant reduction in freezing upon retrieval (unpaired $t$-test, $t=2.88, \mathrm{df}=14, P<0.05$ ) (Fig. $3 \mathrm{C})$ and completely prevented the return of fear in context $\mathrm{A}$ $\left(F_{(3,31)}=3.03, P<0.05\right.$; Tukey's post hoc test; Vehicle Ret vs. 25 $\mathrm{mg} / \mathrm{kg} 7,8$-DHF Ret, $P<0.05$ ) (Fig. 3F). This effect on renewal was due in large part to the very strong effect of 7,8-DHF on contextual memory, as indicated by the pre-CS freezing levels in drug-treated mice $\left(F_{(3,31)}=4.66, P<0.01\right.$; Tukey's post hoc test; Vehicle Ret vs. $25 \mathrm{mg} / \mathrm{kg}$ 7,8-DHF Ret, $P<0.05$ ) (Fig. 3F). Furthermore, this reduction in freezing was not due to a generalized increase in activity as there were no significant differences in locomotion (distance traveled) either $30 \mathrm{~min}$ or $80 \mathrm{~min}$ postinjection (Fig. 3B). Together these data suggest that 7,8-DHF promotes a reduction in fear-related responding during and following extinction training in female mice, consistent with results suggesting that activation of BDNF signaling can induce extinction in the absence of training (Peters et al. 2010).

This study generated three main findings: (1) female mice are resistant to the extinction of conditioned fear; (2) there are sex differences in the epigenetic regulation of $B d n f$ expression in the medial prefrontal cortex; and (3) female mice exhibit a significant return of fear after extinction training in a retrieval-extinction paradigm, effects that are completely blocked by targeted activation of BDNF signaling prior to memory retrieval and extinction training. It is important to note that there is evidence to suggest that sex differences in fear extinction are dependent on circulating gonadal hormone levels (Zeidan et al. 2011; Merz et al. 2012); however, naturally cycling mice were examined in this study to closely mimic what occurs in the general population. Moreover, regardless of cycle, we observed a significant sex difference in fear extinction that is associated with basal differences in epigenetic regulation of $B d n f$ within the medial prefrontal cortex. We cannot exclude the possibility that stage of estrous contributed to these effects (Spencer et al. 2010); however, our data on the return of fear after exposure to a retrieval cue in female mice represent a third replication of this effect, making it unlikely that these differences are strictly due to a hormonal influence on fear extinction learning.

Few studies have considered whether there are sex differences in the epigenetic regulation of gene expression, although this is an emerging concept (McCarthy et al. 2009). Using a mouse model that separates hormonal effects from sex chromosome-linked gene effects, Xu et al. (2008) were the first to examine how genes specifically encoded on sex chromosomes influence the way in which the epigenome exerts an effect on gene expression. They found that, regardless of gonadal phenotype, the expression pattern of the $\mathrm{H} 3 \mathrm{~K} 27^{\mathrm{me} 3}$ histone demethylase ubiquitously transcribed tetratricopeptide repeat gene on X chromosome (Utx) was highest in the cortex of female mice. We have observed a similar pattern of Utx expression specifically in the medial prefrontal cortex in male and female mice (data not shown). Given the tight association between $\mathrm{H} 3 \mathrm{~K} 27^{\mathrm{me}} 3$ and DNA methylation, it is likely that sex differences in the epigenome are broadly distributed and contribute to the function of many genes and related behaviors. Our data on DNA methylation status of $B d n f$ exon IV give but one prototypical example of how sex differences in the epigenetic regulation of gene expression may influence fear-related learning and memory. With respect to the influence of 7,8-DHF on the return of fear, previous studies have indicated beneficial effects of 7,8-DHF on fear extinction in paradigms where diminished capacities for extinction are observed, such as following exposure to an acute stressor (Andero et al. 2011). These 
observations were later extended by the demonstration of a beneficial effect of 7,8-DHF on stress-induced spatial memory impairments (Andero et al. 2012). Thus, exposure to a retrieval cue prior to fear extinction training may represent an acute stressor, which leads to a significant increase in the return of fear in female mice, an effect that can be completely prevented by activation of BDNF signaling.

In summary, female mice are resistant to fear extinction, and exhibit increased DNA methylation of $B d n f$ exon IV and a concomitant decrease in mRNA expression within the medial prefrontal cortex. Together these findings suggest the intriguing possibility that sex differences in epigenetic regulation of gene expression may represent a general distinction between the male and female brain that will impact a variety of behaviors. In the case of BDNF signaling, targeting downstream trkB receptors to block renewal in female mice offers a novel approach to treating fear-related anxiety disorders characterized by a significant return of fear.

\section{Acknowledgments}

We gratefully acknowledge grant support from the Australian Research Council (DP1096148). A postgraduate award from the National Sciences and Engineering Research Council of Canada supports D.B.-A., and X.L. is supported by postgraduate scholarships from the University of Queensland and the ANZ Trustees Queensland for medical research. We would like to also thank Ms. Rowan Tweedale for helpful editing of the manuscript.

\section{References}

Akirav I, Raizel H, Maroun M. 2006. Enhancement of conditioned fear extinction by infusion of the GABA(A) agonist muscimol into the rat prefrontal cortex and amygdala. Eur J Neurosci 23: 758-764.

Andero R, Ressler KJ. 2012. Fear extinction and BDNF: Translating animal models of PTSD to the clinic. Genes Brain Behav 11: 503-512.

Andero R, Heldt SA, Ye K, Liu X, Armario A, Ressler KJ. 2011. Effect of 7,8-dihydroxyflavone, a small-molecule TrkB agonist, on emotional learning. Am J Psychiatry 168: 163-172.

Andero R, Daviu N, Escorihuela RM, Nadal R, Armario A. 2012. 7,8-Dihydroxyflavone, a TrkB receptor agonist, blocks long-term spatial memory impairment caused by immobilization stress in rats. Hippocampus 22: 399-408.

Baker-Andresen D, Ratnu VS, Bredy TW. 2012. Dynamic DNA methylation: A prime candidate for genomic metaplasticity and behavioral adaptation. Trends Neurosci 36: 3-13.

Boulle F, van den Hove DL, Jakob SB, Rutten BP, Hamon M, van Os J, Lesch KP, Lanfumey L, Steinbusch HW, Kenis G. 2012. Epigenetic regulation of the BDNF gene: Implications for psychiatric disorders. Mol Psychiatry 17: 584-596.

Bredy TW, Wu H, Crego C, Zellhoefer J, Sun YE, Barad M. 2007. Histone modifications around individual BDNF gene promoters in prefrontal cortex are associated with extinction of conditioned fear. Learn Mem 14: $268-276$.

Chan WY, Leung HT, Westbrook RF, McNally GP. 2010. Effects of recent exposure to a conditioned stimulus on extinction of Pavlovian fear conditioning. Learn Mem 17: 512-521.

Clem RL, Huganir RL. 2010. Calcium-permeable AMPA receptor dynamics mediate fear memory erasure. Science 330: 1108-1112.

Day JJ, Sweatt JD. 2011. Epigenetic mechanisms in cognition. Neuron 70: 813-829.

Devi L, Ohno M. 2012. 7,8-Dihydroxyflavone, a small-molecule TrkB agonist, reverses memory deficits and BACE1 elevation in a mouse model of Alzheimer's disease. Neuropsychopharmacology 37: 434-444.

Hill RA, van den Buuse M. 2011. Sex-dependent and region-specific changes in TrkB signaling in BDNF heterozygous mice. Brain Res 1384: 51-60.
Jang SW, Liu X, Yepes M, Shepherd KR, Miller GW, Liu Y, Wilson WD, Xiao G, Blanchi B, Sun YE, et al. 2010. A selective TrkB agonist with potent neurotrophic activities by 7,8-dihydroxyflavone. Proc Natl Acad Sci 107: 2687-2692.

Lebron-Milad K, Graham BM, Milad MR. 2012. Low estradiol levels: A vulnerability factor for the development of posttraumatic stress disorder. Biol Psychiatry 72: 6-7.

Liu X, Chan CB, Jang SW, Pradoldej S, Huang J, He K, Phun LH, France S, Xiao G, Jia Y, et al. 2010. A synthetic 7,8-dihydroxyflavone derivative promotes neurogenesis and exhibits potent antidepressant effect. J Med Chem 53: 8274-8286.

McCarthy MM, Auger AP, Bale TL, De Vries GJ, Dunn GA, Forger NG, Murray EK, Nugent BM, Schwarz JM, Wilson ME. 2009. The epigenetics of sex differences in the brain. J Neurosci 29: 12815-12823.

Merz CJ, Tabbert K, Schweckendiek J, Klucken T, Vaitl D, Stark R, Wolf OT. 2012. Neuronal correlates of extinction learning are modulated by sex hormones. Soc Cogn Affect Neurosci 7: 819-830.

Miller CA, Gavin CF, White JA, Parrish RR, Honasoge A, Yancey CR, Rivera IM, Rubio MD, Rumbaugh G, Sweatt JD. 2010. Cortical DNA methylation maintains remote memory. Nat Neurosci 13: $664-666$.

Monfils MH, Cowansage KK, Klann E, LeDoux JE. 2009. Extinctionreconsolidation boundaries: Key to persistent attenuation of fear memories. Science 324: 951-955.

Nader K, Schafe GE, Le Doux JE. 2000. Fear memories require protein synthesis in the amygdala for reconsolidation after retrieval. Nature 406: $722-726$.

Olff M, Langeland W, Draijer N, Gersons BP. 2007. Gender differences in posttraumatic stress disorder. Psychol Bull 133: 183-204.

Peters J, Dieppa-Perea LM, Melendez LM, Quirk GJ. 2010. Induction of fear extinction with hippocampal-medial BDNF. Science 328: $1288-1290$.

Przybyslawski J, Sara SJ. 1997. Reconsolidation of memory after its reactivation. Behav Brain Res 84: 241-246.

Przybyslawski J, Roullet P, Sara SJ. 1999. Attenuation of emotional and nonemotional memories after their reactivation: Role of beta adrenergic receptors. J Neurosci 19: 6623-6628.

Sakata K, Woo NH, Martinowich K, Greene JS, Schloesser RJ, Shen L, Lu B. 2009. Critical role of promoter IV-driven BDNF transcription in GABAergic transmission and synaptic plasticity in the prefrontal cortex. Proc Natl Acad Sci 106: 5942-5947.

Schiller D, Monfils MH, Raio CM, Johnson DC, Ledoux JE, Phelps EA. 2010. Preventing the return of fear in humans using reconsolidation update mechanisms. Nature 463: 49-53.

Spencer JL, Waters EM, Milner TA, Lee FS, McEwen BS. 2010. BDNF variant Val66Met interacts with estrous cycle in the control of hippocampal function. Proc Natl Acad Sci 107: 4395-4400.

Ter Horst JP, Carobrez AP, van der Mark MH, de Kloet ER, Oitzl MS. 2012. Sex differences in fear memory and extinction of mice with forebrain-specific disruption of the mineralocorticoid receptor. Eur J Neurosci 36: 3096-3102.

Tolin DF, Foa EB. 2006. Sex differences in trauma and posttraumatic stress disorder: A quantitative review of 25 years of research. Psychol Bull 132: 959-992.

Xu J, Deng X, Watkins R, Disteche CM. 2008. Sex-specific differences in expression of histone demethylases Utx and Uty in mouse brain and neurons. J Neurosci 28: 4521-4527.

Zeidan MA, Igoe SA, Linnman C, Vitalo A, Levine JB, Klibanski A, Goldstein JM, Milad MR. 2011. Estradiol modulates medial prefrontal cortex and amygdala activity during fear extinction in women and female rats. Biol Psychiatry 70: 920-927.

Zeng Y, Liu Y, Wu M, Liu J, Hu Q. 2012a. Activation of TrkB by 7,8-dihydroxyflavone prevents fear memory defects and facilitates amygdalar synaptic plasticity in aging. J Alzheimers Dis $\mathbf{3 1}$ : $765-778$.

Zeng Y, Lv F, Li L, Yu H, Dong M, Fu Q. 2012b. 7,8-Dihydroxyflavone rescues spatial memory and synaptic plasticity in cognitively impaired aged rats. J Neurochem 122: 800-811.

Zhu SW, Yee BK, Nyffeler M, Winblad B, Feldon J, Mohammed AH. 2006. Influence of differential housing on emotional behaviour and neurotrophin levels in mice. Behav Brain Res 169: 10-20.

Received November 7, 2012; accepted in revised form February 12, 2013. 


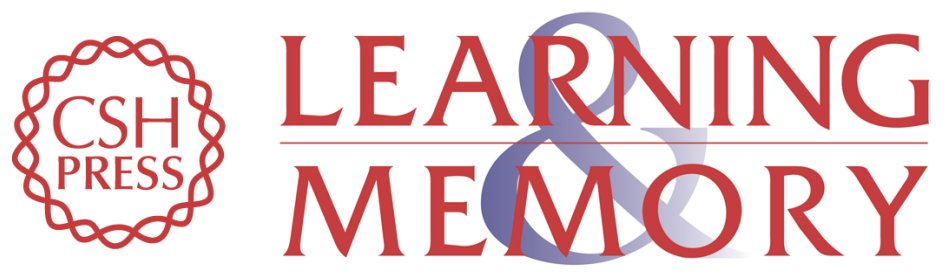

\section{Activation of BDNF signaling prevents the return of fear in female mice}

Danay Baker-Andresen, Charlotte R. Flavell, Xiang Li, et al.

Learn. Mem. 2013, 20:

Access the most recent version at doi:10.1101/Im.029520.112

References This article cites 34 articles, 11 of which can be accessed free at: http://learnmem.cshlp.org/content/20/5/237.full.htmI\#ref-list-1

License

Email Alerting Receive free email alerts when new articles cite this article - sign up in the box at the Service top right corner of the article or click here. 